\section{ZEW}

Zentrum für Europäische Wirtschaftsforschung GmbH

Centre for European Economic Research

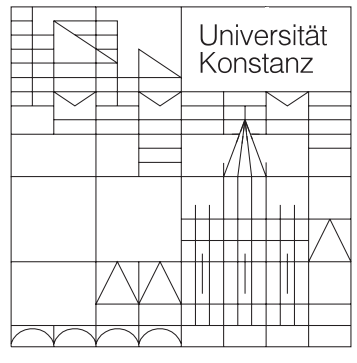

Rechts-, Wirtschafts- und Verwaltungswissenschaftliche Sektion

Fachbereich

Wirtschaftswissenschaften

Diskussionspapiere der DFG-

Forschergruppe (Nr.: 3468269275):

Heterogene Arbeit: Positive und Normative Aspekte der Qualifikationsstruktur der Arbeit

Nikolai Stähler

Firing Costs, Severance Payments, Judicial Mistakes and Unemployment

Februar 2006 
Diskussionspapier der Forschergruppe (Nr.: 3468269275) "Heterogene Arbeit: Positive und Normative Aspekte der Qualifikationsstruktur der Arbeit"

Nr. 06/06, Februar 2006

\title{
Firing Costs, Severance Payments, Judicial Mistakes and Unemployment
}

\author{
Nikolai Stähler \\ Universität Mainz \\ Fachbereich Wirtschaftswissenschaften \\ FB03/LS Goerke \\ 55099 Mainz \\ Germany \\ mail: staehl@uni-mainz.de
}

\section{Zusammenfassung:}

In the discussion about employment protection, little attention has been given to judicial mistakes. In most countries, only in the case of dismissals due to economic reasons, the employee is entitled to a severance payment. Given judicial mistakes when reviewing a dismissal, shirkers might falsely receive a severance payment while non-shirker might not. At fighting unemployment, increasing the level of severance payments can increase employment for small judicial mistakes and effectively dominate the pure firing costs which leave ambiguous effects on employment. For large judicial mistakes, the opposite can hold and severance payments can decrease employment. 


\title{
Firing Costs, Severance Payments, Judicial Mistakes and Unemployment
}

\author{
Nikolai Stähler* \\ University of Mainz \\ February 9, 2006
}

\begin{abstract}
In the discussion about employment protection, little attention has been given to judicial mistakes. In most countries, only in the case of dismissals due to economic reasons, the employee is entitled to a severance payment. Given judicial mistakes when reviewing a dismissal, shirkers might falsely receive a severance payment while non-shirker might not. At fighting unemployment, increasing the level of severance payments can increase employment for small judicial mistakes and effectively dominate the pure firing costs which leave ambiguous effects on employment. For large judicial mistakes, the opposite can hold and severance payments can decrease employment.
\end{abstract}

Theme: Labour Market Policy

Keywords: employment protection, judicial mistakes, matching models, shirking, unemployment

JEL-Code: J 41, J 64, J 65, J 68

\footnotetext{
*Address correspondence to: Nikolai Stähler, University of Mainz, Department of Economics (FB03/LS Goerke), Jakob-Welder-Weg 5, 55099 Mainz, Germany. Email: staehl@uni-mainz.de.

I would like to thank Salvatore Barbaro, Florian Baumann, Laszlo Goerke, Martin Kolmar, Marcus Jansen, and Dorothee Schmidt for helpful comments. Further, I would like to thank participants of the Canadian Economics Association Annual Meeting 2005 and the Work Pension and Labour Economics Conference 2005 for good proposals. Financial support of the Deutsche Forschungsgemeinschaft (DFG) is gratefully acknowledged.
} 


\section{Introduction}

In the discussion about employment protection, it is often claimed that severance payments have some desirable advantages compared to pure firing costs. Firing costs are usually modelled to be "waste that disappears" when a dismissal takes place, while severance payments are paid to the worker in case he is laid off. This yields an advantage of severance payments over pure firing costs, i.e. that workers accept lower wages and, therefore, the firms' incentive of job creation increases (see Lazaer 1990). This has been confirmed by, e.g., Fella (2000), Goerke (2002), and Garibaldi and Violante (2005). In political discourse, especially in continental Europe, the demand for a system of severance payments is steadily rising. For example, in Germany, the German Council of Economic Experts has repeatedly proposed a switch from a system of pure firing restrictions to a system of severance payments in their report of the year 2005. The models mentioned above highlighting the superiority of severance payments over pure firing costs consider full information where only those workers that are entitled actually receive the payment.

In most countries, only operational dismissals involve severance payments, while no severance payments have to be paid due to disciplinary or personal dismissals (OECD 2004). This evokes the incentive for firms to claim the dismissal to be a disciplinary or personal one, while workers claim it to be an operational one. The employee is mostly entitled to insist on a judicial review of the dismissal (OECD 2004). That gives room to the assumption that judges or juries possibly make mistakes in such a review. The judicial review of the dismissal can create two types of mistakes. First, mistakenly allowing someone who is not entitled to a severance payments (in the following, a shirker) to receive one, type I. Second, not allowing someone who is entitled to a severance payment (in the following, a non-shirker) to receive one, type II. The existence of those mistakes might change the results about the positive employment effect of severance payments (see below).

In theoretical literature, the implications of judicial mistakes have hardly been discussed. One of the first and only papers to analyze the implications of the existence of judicial mistakes on employment is by Galdón-Sánches and Güell (2003). They present a modified efficiency wage model in the manner of Shapiro and Stiglitz (1984) with severance payments. They claim that in the presence of judicial mistakes, "disciplinary dismissals will not be costless and firing costs will have a negative effect on aggregated employment" (GaldónSánches and Güell 2003, p. 323). This is mainly due to the fact that the severance payment cannot be fully neutralized through an accordant decrease of wages as in complete and perfect markets by anticipating these payments as it is in Lazear (1990). In their model, Galdón-Sánches and Güell (2003) take operational dismissals as an exogenous event, which highly drives their results. They do not compare severance payments to pure firing costs.

In the present paper, we will do two things. First, we introduce the firm's decision of when to dismiss a worker. The effect of increasing the level of severance payments on unemployment will be by far less clear cut in the presence of judicial mistakes as is claimed by Galdón-Sánches and Güell (2003). The main reason for the difference is that workers 
will have to be compensated for a higher risk of dismissal through higher wages when firms decide to dismiss earlier. Second, we compare pure firing costs with severance payments.

The problem is analyzed in a matching model according to Pissarides (2000) to be able to explicitly model operational dismissals and the decision of job creation endogenously. To introduce true disciplinary dismissals, the matching model is augmented by the possibility of shirking in the manner of Shapiro and Stiglitz (1984). We show theoretically that a reduction of type I and type II mistakes decreases unemployment. This is due to the fact that decreasing insecurity of dismissal costs lowers expected labour costs and, therefore, unemployment. Furthermore, we see that an increase of the level of severance payments itself has ambiguous effects on job creation and job destruction and, therefore, on unemployment. It does not necessarily increase unemployment as claimed by Galdón-Sánches and Güell (2003). While we are able to derive clear theoretical conditions for unemployment to decrease we cannot say if they are fulfilled. This shows that it is essential to do more empirical research to clarify these conditions and to be able to give political advice and evaluate political actions.

The rest of the paper is organized as follows. In section 2, we will introduce the model. Section 3 contains a comparative static analysis. Last, in section 4, the main findings are summarized. For important calculations, a mathematical appendix is added.

\section{The Model}

\subsection{Basic Structure}

We consider an economy with a continuum of infinitely lived, homogeneous workers. The continuum is normalized to one. Firms are also measured in a continuum, while free market entry determines their number. The discount rate of workers and firms is $r$. Workers' instantaneous utility function is given by $V(w, e)=w-e$, where $w$ is the wage income and $e$ characterizes the cost of effort when working.

Following Pissarides (2000), all firms are identical and have one vacancy to offer. The labour market is characterized by search frictions. Unemployment $u$ and vacancies $v$ exist at the same time. The production flow of a firm-worker match is described in a value function and shall in the following be called job. The matching process is described by a linear homogeneous and concave matching function $m(v, u)$. The ratio $\theta=v / u$ is called market tightness. It is determined endogenously. The rate at which vacancies are filled is given by $q(\theta)=m(1 / \theta, 1)$, where $q^{\prime}(\theta)<0$. Unemployed workers find a job at rate $\theta q(\theta)=m(\theta, 1)$, where $[\theta q(\theta)]^{\prime}>0$. Furthermore, each job has an idiosyncratic productivity component $\epsilon \in\left[\epsilon_{l}, \epsilon_{u}\right]$, which is distributed according to the cumulative and continuously differentiable distribution function $G(\epsilon)$, with $g(\epsilon)>0$ being the corresponding density function. Productivity shocks occur to every single job at the Poisson rate $\lambda$. In the case of a shock, a new idiosyncratic productivity is drawn from the distribution $G(\epsilon)$. If the productivity falls below some endogenously determined threshold value (which is called reservation productivity), the job is destroyed. 
We assume that according to Shapiro and Stiglitz (1984), firms need the worker to work at an effort level $e=\bar{e}$ to be productive. That is, when employed, the worker decides if he provides the effort level or not. Effort is a binary choice. Workers can either work (at the effort $e=\bar{e}$ ) or shirk (where the effort level is $e=0$ ). Inspections occur according to a Poisson process with arrival rate $q$ and are costless. If a worker is found shirking, at $e=0$, he is dismissed.

Workers are entitled to receive a severance payment $S$ when they are dismissed due to operational reasons. If dismissed due to disciplinary reasons (shirking), workers miss out. This gives the incentive for firms to claim the dismissal has taken place due to shirking, even though it has been due to a productivity shock. Workers have the incentive to claim that the dismissal has taken place due to operational reasons even though it was due to disciplinary ones. This conflict is taken to court. ${ }^{1}$ When laying off a worker, firms have to pay a severance payment $S$ to the worker in the case of an operational dismissal and firing costs $T$ to some third party not explicitly modeled. Judges might make mistakes in the reviewing process. Therefore, following Güell (1999), with exogenous probability $m$, true disciplinary dismissals are mistakenly judged to be operational layoffs. With probability $(1-z)$, redundancies are mistakenly judged to be disciplinary dismissals.

\subsection{The Value Functions}

\section{Workers}

The value function for an employed worker, denoted by $W$, who maximizes his life-time utility, satisfies the following Bellman equation

$$
\begin{aligned}
& r W= \\
& \max _{e=0 \text { or } e=\bar{e}}\left\{w-e+\lambda\left[\int_{\epsilon_{d}}^{\epsilon_{u}} W d G(\epsilon)+G\left(\epsilon_{d}\right)(U+z S)-W\right]+q l(e)[U+m S-W]\right\},
\end{aligned}
$$

where $w$ is the wage the worker earns. $l(e)$ is a function of the effort $e$ which equals one in the case of $e=0$ and is zero in the case of $e=\bar{e}$. Therefore, the "asset pricing" function for an employed worker is influenced by the wage minus the effort plus the option value in the case of a productivity shock and the option value in the case a shirking worker is dismissed. If productivity falls below the reservation productivity $\epsilon_{d}$, the match is resolved and the worker becomes unemployed. In this case, the worker obtains the utility of an unemployed worker $U$ and a redundancy payment $S$ with probability $z$. If the productivity after the shock does not fall below the reservation productivity, the employment relationship continues, which is expressed in the integral over $\epsilon_{d}$ to $\epsilon_{u}$, as a new productivity is drawn from the distribution

\footnotetext{
${ }^{1}$ Note that in the below described model, all disputes are settled in court, because no costs occur from taking the dispute there. Since we are interested in the isolated effects of judicial mistakes, this simplifying assumption does not harm the following analysis. For a first, simple approach of introducing costs associated with going to court, see Galdón-Sánches and Güell (2003). Even there, everybody goes to court as long as the expected benefit from going to court is higher than the punishment when caught lying.
} 
function $G(\epsilon)$. In case the worker is fired due to disciplinary reasons, the worker also receives the utility of unemployment and the redundancy payment $S$ with probability $m$.

The "asset pricing" function of unemployment can be stated as

$$
r U=\theta q(\theta)[W-U] .
$$

For simplicity we abstract from non-labour income. Therefore, the utility flow of unemployment equals the option value of finding a job.

To prevent shirking, the worker must get a high enough rent from working for shirking not to pay, i.e. $\underset{e=\bar{e}}{W} \geq \underset{e=0}{W}$. This gives the non-shirking-condition (NSC),

$$
W-U \geq \frac{\bar{e}}{q}+m S
$$

Equation (3) states that a shirker saves the work disutility $\bar{e}$, but bears a capital loss $W-U$ if he is fired after being caught shirking. This event occurs at Poisson rate $q$. When being fired, a shirker additionally receives a redundancy pay $S$ with probability $m$.

Using equation (1) in combination with equation (3), the latter can be transformed to

$$
w^{e} \geq r U+\bar{e}+\left(r+\lambda G\left(\epsilon_{d}\right)\right)\left[\frac{\bar{e}}{q}+m S\right]-\lambda G\left(\epsilon_{d}\right) z S,
$$

where $w^{e}$ is the non-shirking wage. $r U+\bar{e}$ represents the opportunity cost from working, $\left(r+\lambda G\left(\epsilon_{d}\right)\right)\left[\frac{\bar{e}}{q}+m S\right]$ the annuity of the rent and $\lambda G\left(\epsilon_{d}\right) z S$ the "belated" wage payment in form of severance payments according Lazear (1990). Using equation (2) to eliminate $U$, we obtain

$$
\left.w^{e}=\bar{e}+\left[r+\theta q(\theta)+\lambda G\left(\epsilon_{d}\right)\right)\right]\left[\frac{\bar{e}}{q}+m S\right]-\lambda G\left(\epsilon_{d}\right) z S .
$$

As long as the NSC is fulfilled, no worker shirks in equilibrium. If it is not, all workers shirk. A high effort level, represented by $\bar{e}$, and high re-employment probability, represented by $\theta q(\theta)$, clearly increase the non-shirking wage, as they increase the opportunity costs of working. Further, high type I mistakes, high $m$, increase the non-shirking wage. That is because, through high type I mistakes, shirkers can falsely receive severance payments in the case of being caught shirking, which increases the incentive to shirk. Low type II mistakes, high $z$, decrease the non-shirking wage, as the expected compensation for a job loss is high, which makes shirking less attractive. Due to the fact that effort of workers is not perfectly observable and judicial mistakes exist, severance payments might reduce workers' incentive to provide effort, which has empirically been confirmed by Riphahn (2004). Intuitively, a high dismissal probability, represented by $\lambda G\left(\epsilon_{d}\right)$, increases the non-shirking wage, as workers have to be compensated for the higher risk of a job loss. Fella (2000) already pointed out that for no judicial mistakes $(m=0$ and $z=1)$, and for $S=\frac{\bar{e}}{q}\left(S>\frac{\bar{e}}{q}\right)$, the worker gets fully (over)compensated for the risk of losing the job. As the severance payment in the above 
model framework is assumed to be legally determined as in Staffolani (2002), we assume without loss of generality that there is no overprotection and that, therefore, $(z-m) S<\frac{\bar{e}}{q}$ holds. Also, a high level of severance payments should decrease the non-shirking wage, as workers get compensated for their job loss by the "belated wage payment" (see again, e.g., Fella 2000). In the presence of judicial mistakes, this effect is ambiguous, as the incentive for shirking also increases with higher severance payments. A high enough type II mistake, low $z$, can lead to an increase of the non-shirking wage when severance payments are increased. For a given $\epsilon_{d}$, this is the case if $\frac{m}{z}>\frac{\lambda G\left(\epsilon_{d}\right)}{r+\lambda G\left(\epsilon_{d}\right)+\theta q(\theta)}$ (see equation (4)). ${ }^{2}$

\section{Firms}

Analogously to the argumentation of the workers' optimization problem, the firm's Bellman equation can be written as

$$
r J(\epsilon)=\bar{e} \epsilon-w^{e}+\lambda\left[\int_{\epsilon_{d}}^{\epsilon_{u}} J(x) d G(x)-G\left(\epsilon_{d}\right)(z S+T)-J(\epsilon)\right] .
$$

The firms' "asset pricing" function therefore consists of the effort level needed, $\bar{e}$, multiplied with the idiosyncratic productivity minus the non-shirking wage plus the option value of a shock. In the case that productivity falls short of the reservation productivity $\epsilon_{d}$, the firm has to pay firing costs $T$ and a severance payment $S$ with probability $z$. As the firms know that they have to pay at least the non-shirking wage (equation (4)) to prevent workers from shirking for all wages $w$ below the non-shirking wage, the job would be closed.

The Bellman equation for a vacancy $V$ can be derived in the same manner. Following Pissarides (2000), newly created jobs are endowed with the highest possible productivity, $\epsilon_{u}$. Recruitment costs are given by $c>0$ per period.

$$
r V=-c+q(\theta)\left[J\left(\epsilon_{u}\right)-V\right] .
$$

Free market entry for firms implies that vacancies will be created as long as their present value is greater than zero. Accordingly, in equilibrium, $V=0$ has to hold, yielding

$$
J\left(\epsilon_{u}\right)=\frac{c}{q(\theta)} .
$$

Equation (7) states that the value of a newly created job has to equal average search costs.

\subsection{Job Destruction, Job Creation, and Unemployment}

For given policy parameters and judicial mistakes, the market equilibrium is defined by the two endogenous variables market tightness, $\theta$, and reservation productivity, $\epsilon_{d}$, governing

\footnotetext{
${ }^{2}$ Note that for the case of no judicial mistakes, $m=0$ and $z=1$, the non-shirking wage decreases with increasing severance payments through the "belated wage payment" as in Lazear (1990) or Fella (2000). Through judicial mistakes, this is weakened and might be reversed.
} 
the processes of job creation and job destruction. As long as the expected value of a job exceeds the expected dismissal costs, the job will stay on the market. Therefore, reservation productivity is determined by

$$
J\left(\epsilon_{d}\right)=-(z S+T) .
$$

As stated earlier, market tightness $\theta$ is determined by free market entry for firms, equation (7). Substituting the wage equation (4) into value of the firm, equation (5), and using the above described job destruction condition, as well as equation (7), we derive (for calculations see Appendix A)

$$
\begin{aligned}
& \bar{e} \epsilon_{d}+\frac{\lambda \bar{e}}{r+\lambda} \int_{\epsilon_{d}}^{\epsilon_{u}}\left(\epsilon-\epsilon_{d}\right) d G(\epsilon)+\lambda G\left(\epsilon_{d}\right) z S= \\
& \bar{e}+\left[r+\lambda G\left(\epsilon_{d}\right)+\theta q(\theta)\right]\left[\frac{\bar{e}}{q}+m S\right]-r(z S+T)
\end{aligned}
$$

as the job destruction condition (further JD) and

$$
\frac{\bar{e}\left[\epsilon_{u}-\epsilon_{d}\right]}{(r+\lambda)}-(z S+T)=\frac{c}{q(\theta)}
$$

as the job creation condition (further JC).

Equations (8) and (9) simultaneously determine the equilibrium values of reservation productivity $\epsilon_{d}$ and market tightness $\theta$ for given policy parameters $S, T$ and the judicial mistakes $m$ and $z$.

Note that the possibility of multiple equilibria exists. While the JC has a negative slope in the $\epsilon_{d}-\theta$-space, the JD does not necessarily have a positive slope. It might partly be negatively sloped or S-shaped as presented in figure 1 . This is due to the positive feedback between the efficiency wage, $w^{e}$, and the reservation productivity. An increase of the reservation productivity, $\epsilon_{d}$, increases the lhs and the rhs of the JD, equation (8). Because the wage also increases with market tightness, $\theta$, (see equation (4)) it can be shown that a necessary and sufficient condition for the JD to have a negative slope is $\lambda g\left(\epsilon_{d}\right)\left[\frac{\bar{e}}{q}+(m-z) S\right]>\frac{\bar{e}}{r+\lambda}\left[r+\lambda G\left(\epsilon_{d}\right)\right]$, which means that the marginal effect of an increase of reservation productivity on wages exceeds the marginal increase of the production value of a job at reservation productivity, the lhs of equation (8), see also Mortensen and Pissarides (1999).

Unemployment is determined by inflows $\left(\lambda G\left(\epsilon_{d}\right)(1-u)\right)$ and outflows $(\theta q(\theta) u)$ according to the job destruction and job creation decisions of firms. The equilibrium unemployment is, therefore, also determined by the equilibrium values of reservation productivity and market tightness. In steady state, the change in unemployment is zero and the unemployment rate is given by

$$
u=\frac{\lambda G\left(\epsilon_{d}\right)}{\lambda G\left(\epsilon_{d}\right)+\theta q(\theta)} .
$$




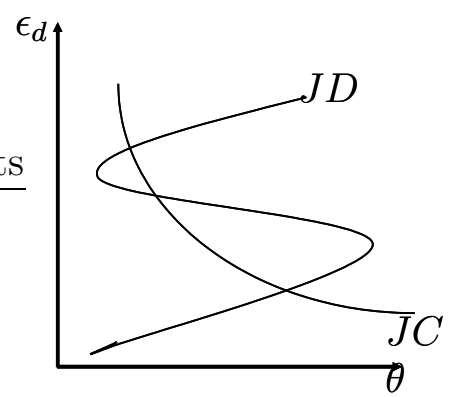

Figure 1: Possible Multiple Equilibria

Since, as already mentioned above, no worker shirks in equilibrium, because firms pay the non-shirking wage, no inflows into unemployment result from real disciplinary dismissals in equilibrium.

\section{Changes in Firing Costs, Judicial Mistakes and Sev- erance Payments}

In the following section, we will analyze the effects of a change of the level of pure firing costs, type I mistake, type II mistake and the level of severance payments. The effects are summarized in table 1. Further, we discuss the results and compare the effects of severance payments to those of firing costs. Calculations can be retraced in Appendix B.

\subsection{Increasing firing costs $T$}

By totally differentiating the JD and the JC, we find that an increase of the level of firing costs yields

$$
\frac{d \epsilon_{d}}{d T}=\frac{1}{D}\left\{-r \frac{c}{q(\theta)^{2}} q^{\prime}(\theta)+[\theta q(\theta)]^{\prime}\left[\frac{\bar{e}}{q}+m S\right]\right\}
$$

and

$$
\frac{d \theta}{d T}=\frac{1}{D}\left\{\frac{\bar{e}}{r+\lambda} \lambda G\left(\epsilon_{d}\right)-\lambda g\left(\epsilon_{d}\right)\left[\frac{\bar{e}}{q}+(m-z) S\right]\right\}
$$

where

$$
\begin{aligned}
D= & {\left[\frac{\bar{e}}{r+\lambda}\left(r+\lambda G\left(\epsilon_{d}\right)\right)-\lambda g\left(\epsilon_{d}\right)\left[\frac{\bar{e}}{q}+(m-z) S\right]\right] \frac{c}{q(\theta)^{2}} q^{\prime}(\theta) } \\
& -\frac{\bar{e}}{r+\lambda}\left[\frac{\bar{e}}{q}+m S\right][\theta q(\theta)]^{\prime} .
\end{aligned}
$$

The sign of equation (13) is ambiguous. $D$ represents the Jakobi matrix of the system of equations (8) and (9) for the changes of reservation productivity $\epsilon_{d}$ and market tightness $\theta$. If the equilibrium is located on the upward sloping part of the JD, $D<0$, as 
$\left[\frac{\bar{e}}{r+\lambda}\left(r+\lambda G\left(\epsilon_{d}\right)\right)-\lambda g\left(\epsilon_{d}\right)\left[\frac{\bar{e}}{q}+(m-z) S\right]\right]>0$. Therefore, this equilibrium is locally stable. Only if the equilibrium is located on the downward sloping part of the JD, $D>0$ is possible. In this case $\left[\frac{\bar{e}}{r+\lambda}\left(r+\lambda G\left(\epsilon_{d}\right)\right)-\lambda g\left(\epsilon_{d}\right)\left[\frac{\bar{e}}{q}+(m-z) S\right]\right]<0$. The equilibrium is locally stable as well, because $\left[\frac{\bar{e}}{r+\lambda}\left(r+\lambda G\left(\epsilon_{d}\right)\right)-\lambda g\left(\epsilon_{d}\right)\left[\frac{\bar{e}}{q}+(m-z) S\right]\right]+\frac{c}{q(\theta)^{2}} q^{\prime}(\theta)<0$. Nevertheless, we know from empirical literature that an increase of firing costs decreases dismissal probability (reservation productivity) and job creation (market tightness). ${ }^{3}$ Also, most theoretical works, as, e.g., Bertola (1990), Garibaldi (1998), Mortensen and Pissarides (1999) or Pissarides (2001) approve this result. In the above model framework, this can only be the case if the equilibrium is located on the upward sloping part of the JD, because only there both terms in brackets of equations (11) and (12) are positive, while $D<0$. In accordance with empirical and theoretical findings we therefore assume that this relationship holds in the present model as well and $D<0$ shall be assumed henceforth.

Equations (11) and (12) then show that reservation productivity and market tightness unambiguously decrease when firing costs are increased, while the effect on unemployment is ambiguous due to fewer dismissals and less job creation, as can be seen in equation (10). As dismissals get more expensive, it is clear that reservation productivity and, therefore, dismissal probability decreases. It is also straightforward to argue that through higher firing costs, the value of newly created jobs decreases, and, therefore, in equilibrium, market tightness decreases.

\subsection{Increasing the type I mistakes $m$}

For an increase of type I mistakes, we find again, after totally differentiating the JD and JC, that

$$
\frac{d \epsilon_{d}}{d m}=\frac{1}{D}\left\{\frac{c}{q(\theta)^{2}} q^{\prime}(\theta)\left[\left(r+\lambda G\left(\epsilon_{d}\right)+\theta q(\theta)\right] S\right\}>0\right.
$$

and

$$
\frac{d \theta}{d m}=\frac{1}{D}\left\{\frac{\bar{e}}{r+\lambda}\left[\left(r+\lambda G\left(\epsilon_{d}\right)+\theta q(\theta)\right] S\right\}<0,\right.
$$

for $D<0$. Equation (14) shows that reservation productivity increases with the increasing judicial mistakes of falsely allowing a shirker redundancy payments. Market tightness decreases when doing so (see equation (15)).

The reason for this is straightforward. As can be seen in equation (4), a greater judicial mistake rate $m$ increases the non-shirking wage, which is the minimum wage that firms have to pay. Higher wages yield higher labour costs. Therefore, reservation productivity increases. The increase of reservation productivity additionally increases the non-shirking wage. As

\footnotetext{
${ }^{3}$ A variety of empirical papers confirms this result, see Addison and Teixeira (2003), Baker et al. (2005) Blanchard and Portugal (2001) and Scarpetta (1996), just to mention a few. Also, it has again been approved by the OECD (OECD 2004).
} 
working costs increase, relatively less jobs are more productive. The value of newly created jobs decreases and, therefore, fewer vacancies are offered.

Thus, increasing the judicial mistakes of falsely allowing a shirker to receive severance payments increases reservation productivity and decreases market tightness. This makes unemployment unambiguously rise if type I mistakes increase, as can be seen in equation $(10)$.

\subsection{Increasing the type II mistakes $(1-z)$}

For the change of the type II mistakes of falsely not allowing a non-shirker to receive a severance payment, we find after totally differentiating the JD and JC for $D<0$ that

$$
\frac{d \epsilon_{d}}{d z}=\frac{1}{D}\left\{-\frac{c}{q(\theta)^{2}} q^{\prime}(\theta)\left(r+\lambda G\left(\epsilon_{d}\right)\right)+\left[\frac{\bar{e}}{q}+m S\right][\theta q(\theta)]^{\prime}\right\} S<0,
$$

and

$$
\frac{d \theta}{d z}=\frac{1}{D}\left\{-\lambda g\left(\epsilon_{d}\right)\left[\frac{\bar{e}}{q}+(m-z) S\right]\right\} S>0 .
$$

Note that to be consistent with the above part, when analyzing the effect of an increase of type I mistakes, we will also analyze an increase of type II mistakes here. But because the type II mistake rate is defined as $(1-z)$, an increase of type II mistakes implies $d z<0$.

Equation (16) shows that reservation productivity increases with increasing judicial mistake of falsely not allowing a non-shirker for redundancy pays. Market tightness decreases when doing so (see equation (17)).

This can be explained as follows. First, an increase in the judicial mistakes $(1-z)$ increases the non-shirking wage, because workers have to be compensated for the loss of security of receiving a severance payment when being dismissed as a non-shirker (see equation (4)). Labour costs increase. Second, the expected costs of dismissals $(z S)$ decrease, which makes the firm decide to lay off workers earlier according to the JD (see equation (8)). Therefore, reservation productivity increases. Through higher wage costs, the value of newly created firms decreases. Even though the expected firing costs $z S$ decrease, it is overcompensated by the wage increase. This is due to the fact that regarding wages, the decrease of expected severance payments cannot overcompensate the increase of reservation productivity which includes the extra risk compensation. Thus, in total, the value of a newly created job decreases, which decreases the offer of vacancies and, therefore, market tightness (see equation (17)).

Hence, increasing the judicial mistakes $(1-z)$ increases reservation productivity and market tightness. This yields more dismissals, and at the same time, less job creation. Therefore, a higher type II mistake yields a higher unemployment rate (see equation (10)). 


\subsection{Increasing the level of severance payments $S$}

A change of the level of severance payments yields

$$
\frac{d \epsilon_{d}}{d S}=\frac{1}{D}\left\{\left(\frac{c}{q(\theta)^{2}} q^{\prime}(\theta)\left(\left(r+\lambda G\left(\epsilon_{d}\right)+\theta q(\theta)\right) m-\left(r+\lambda G\left(\epsilon_{d}\right)\right) z\right)\right)+[\theta q(\theta)]^{\prime}\left[\frac{\bar{e}}{q}+m S\right] z\right\},
$$

and

$$
\frac{d \theta}{d S}=\frac{1}{D}\left\{\left(\frac{\bar{e}}{r+\lambda}\left(r+\lambda G\left(\epsilon_{d}\right)+\theta q(\theta)\right)\right) m-\lambda g\left(\epsilon_{d}\right)\left[\frac{\bar{e}}{q}+(m-z) S\right] z\right\} .
$$

Equations (18) and (19) show that the effects of an increase of the level of severance payments on reservation productivity and market tightness are ambiguous. They crucially depend on the magnitude of both types of judicial mistakes.

Through an increase of the level of severance payments, expected dismissal costs $z S$ unambiguously increase. That gives incentive for firms to decrease reservation productivity, as dismissals get more expensive. Additionally, increasing the level of severance payments has an effect on the non-shirking wage. This effect is ambiguous due to the existence of judicial mistakes (see equation (4)). We know from equation (18) that reservation productivity increases (yielding more dismissals) due to an increase of the level of severance payments if

$$
\frac{m}{z}>\frac{r+\lambda G\left(\epsilon_{d}\right)}{r+\lambda G\left(\epsilon_{d}\right)+\theta q(\theta)}-\frac{1}{\left(r+\lambda G\left(\epsilon_{d}\right)+\theta q(\theta)\right) \frac{c q^{\prime}(\theta)}{q(\theta)^{2}}} \frac{d w^{e}}{d \theta},
$$

where $\frac{d w^{e}}{d \theta}=[\theta q(\theta)]^{\prime}\left[\frac{\bar{e}}{q}+m S\right]>0$. From equation (19), we find that market tightness unambiguously decreases if

$$
\frac{m}{z}>\frac{\lambda g\left(\epsilon_{d}\right)\left[\frac{\bar{e}}{q}+(m-z) S\right]}{\frac{\bar{e}}{r+\lambda}\left(r+\lambda G\left(\epsilon_{d}\right)+\theta q(\theta)\right)}<1 .
$$

The combination of equations (20) and (21) shows that if equation (20) holds, equation (21) must hold as well as the rhs of equation (20) exceeds the one of equation (21). ${ }^{4}$ The reasoning for reservation productivity to increase and market tightness to decrease as long as equations (20) and (21) hold is as follows: Equation (20) states that reservation productivity increases with the level of severance payments if the relation of the probability of having to pay a severance payment to a shirker and the probability of having to pay a severance payment to a non-shirker is in a way such that the increase of (direct) labour costs is not compensated by the decrease of (indirect) costs resulting from the anticipated decrease of market tightness. Otherwise, reservation productivity will decrease. This gets obvious when decomposing equation (20) into its three components.

\footnotetext{
${ }^{4}$ Because for $D<0,\left[\frac{\bar{e}}{r+\lambda}\left(r+\lambda G\left(\epsilon_{d}\right)\right)-\lambda g\left(\epsilon_{d}\right)\left[\frac{\bar{e}}{q}+(m-z) S\right]\right]>0$ holds. Further, the rhs of equation (21) must be smaller than one due to the same argument.
} 
First, from differentiating equation (4) with respect to $S$, we know that an increase of the level of severance payments increases the non-shirking wage, if $\frac{m}{z}>\frac{\lambda G\left(\epsilon_{d}\right)}{r+\lambda G\left(\epsilon_{d}\right)+\theta q(\theta)}$, i.e., because the type I mistake rate is relatively large, the potential rise of the incentive not to shirk due to the "belated wage payment" cannot compensate the increase of the incentive to shirk due to the fact that shirkers falsely receive severance payments. This augments wage costs and makes firms want to raise reservation productivity on the one hand.

Second, on the other hand, higher severance payments increase dismissal costs and, therefore, make the firm want to decrease reservation productivity, expressed by the term $\frac{r}{r+\lambda G\left(\epsilon_{d}\right)+\theta q(\theta)}$ (see equation (8)). This second effect could theoretically compensate for the first effect which means that the type I mistake rate must relatively increase to a type II mistake rate (expressed by the relation $\frac{m}{z}$ ) for reservation productivity to be increased by the firm.

Third, the simultaneous increase of reservation productivity and the level of severance payments reduces market tightness as the value of newly created jobs decreases. In equilibrium, this is anticipated by the firm when deciding about the change of reservation productivity. Decreasing market tightness decreases the non-shirking wage $\left(\frac{d w^{e}}{d \theta}>0\right)$ and search costs $\left(-\frac{c}{q(\theta)^{2}} q^{\prime}(\theta)>0\right)$. This reduces labour costs and gives incentive to decrease reservation productivity. Again, if the relation of type I mistake to type II mistake is big enough (equation (20) holds), this effect is compensated by the direct wage increase resulting from an increase of the level of severance payments.

Summing up, we can say that as long as euqation (20) holds and, therefore, equation (21) holds as well, an increase of the level of severance payments raises reservation productivity and decreases market tightness. Therefore, unemployment unambiguously increases (see equation (10)).

If equation (20) does not hold, but equation (21) does, reservation productivity and market tightness decrease. In this case, the direct increase of labour costs resulting from an increase of reservation productivity is overcompensated by the indirect decrease resulting from the anticipation of the decrease in market tightness. This reduces reservation productivity. But the fall of reservation productivity, which increases the value of newly created jobs, cannot compensate the direct negative effect of a decrease of the value of newly created jobs resulting from the increase of the level of severance payments (see equation (21)). Therefore, market tightness still falls. The effect on unemployment is ambiguous due to fewer dismissals and less job creation.

If neither equation (20) nor equation (21) hold, reservation productivity decreases and market tightness increases when increasing the level of severance payments. Hence, unemployment decreases due to fewer dismissals and more job creation.

\subsection{Summary and Discussion}

From a theoretical point of view, the effects of pure firing costs on reservation productivity and market tightness are not clearly cut in a model framework with the possibility of 
shirking and endogenous dismissal decision as presented above, because there is a positive feedback between the non-shirking wage and reservation productivity (see also Mortensen and Pissarides 1999). Still, it seems reasonable to assume that pure firing costs decrease the dismissal probability and job creation (which yields an ambiguous effect on unemployment). This is confirmed by a huge amount of theoretical and empirical studies, as shown in section 3.1. Nevertheless, it has to be mentioned that assuming this coherence in the model presented above (and, therefore, $D<0$ ) highly drives the results. If we actually found ourselves in the implausible situation where the equilibrium is located on the downward sloping part of the JD and $D>0$, the above results would change signs.

A very clear point of the above analysis is that judicial mistakes, both type I and type II, increase unemployment. This becomes easily obvious in sections 3.2 and 3.3. Therefore, it seems desirable to keep those mistakes small if one is interested in a low unemployment rate. The model does not analyze where those mistakes come from and takes them as exogenously given. It simply highlights the implications the existence of those mistakes has. If we accept that such mistakes exist, we then see that they have negative effects on employment. This paper clearly gives the assignment to empirical researchers to estimate the magnitudes of those mistakes to see if the topic does have relevance. For theoretical researchers, the assignment is to investigate the origin of those mistakes and to examine a cost/benefit analysis to see if the costs to reduce these mistakes can be compensated by the benefits of a low unemployment rate. So far, there is no empirical literature estimating the magnitude of judicial mistakes. But the existing literature hints that those mistakes do exist. Bertola et al. (1999) find that in Spain and France about one employee in 200 appealed to the courts in 1995. In those countries, over $70 \%$ of the cases were won by workers. For Germany, in 2001, $27 \%$ of all dismissal disputes were taken to court (German Council of Economic Experts 2003). Also, Goerke and Pannenberg (2004) find in a more detailed analysis that between 1990 and 2002 in Germany, on average, 14\% of all employment relationships terminated were accompanied by severance payments. Additionally, Ichino et al. (2003) find that in Italy, $22 \%$ of all dismissals are taken to court and after all, $17 \%$ of the dismissals are overruled by court. Furthermore, they show in an empirical and (game) theoretical approach that judges might be biased by the labour market situation when settling the dismissal dispute. They find out that a bad labour market situation can influence judges' decision in favor of the worker. ${ }^{5}$ Also, Berger (1998) finds that court rules have been significantly more in favor of workers in phases of downswings in Western Germany. This at least allows for the assumption that a judicial review needs some interpretation and errors might occur (either by mistake or even deliberately). For a good overview of existing regulations concerning emplyoment protection laws and severance payments, see Bertola et al. (1999) or OECD (2004). Bertola et al. (1999), too, hint at the fact that judicial mistakes most probably exist, but also say that it is very hard to gather decent data about this issue.

What is not so clear is the effect of an increase of the level of severance payments on

\footnotetext{
${ }^{5}$ Ichino et al. (2003) use firm level data of one specific firm which they do not name. Therefore, the empirical results might not reflect the situation in Italy.
} 
unemployment. As section 3.4 shows, the effect can be ambiguous due to fewer dismissals and less job creation, or positive due to more dismissals and less job creation, or negative due to fewer dismissals and more job creation. This depends on the relation of the type I and type II mistake rates. Table 1 summarizes the effects from the above presented theoretical analysis, where $(+)$ indicates a positive, $(-)$ a negative and (?) an ambiguous effect.

\begin{tabular}{|l|ccc|}
\hline Change of & \multicolumn{3}{|c|}{ Reaction of } \\
& $d \epsilon_{d}$ & $d \theta$ & $d u$ \\
\hline$d m>0$ & $(+)$ & $(-)$ & $(+)$ \\
\hline$d z<0$ & $(+)$ & $(-)$ & $(+)$ \\
\hline$d T>0$ & $(-)$ & $(-)$ & $(?)$ \\
\hline$d S>0$ & $(?)$ & $(?)$ & $(?)$ \\
\hline
\end{tabular}

Table 1: Effects of $d m, d z, d T$, and $d S$

Despite the ambiguity of the effect of an increase of the level of severance payments, we are able to keep hold of the following. If there were no judicial mistakes or if they are relatively small ( $m \approx 0$ and $z \approx 1$ ), an increase of the level of severance payments decreases unemployment as has been shown in section 3.4. Therefore, in this case, severance payments effectively dominate pure firing costs in fighting unemployment as claimed by the authors mentioned in section 1 . The opposite holds for very large judicial mistakes $(m \approx 1$ and $z \approx 0)$. In all the cases in between those extremes, the analysis of section 3.4 applies.

Putting those results into the perspective of existing literature, we can now say that the result by Galdón-Sánches and Güell (2003), namely that an increase of the level of severance payments unambiguously increases unemployment, only holds for large judicial mistakes or a relatively large type I mistake in relation to the type II mistake. Their results only represent a possible outcome and are very much driven by the assumption that no endogenous dismissal probability and, therefore, no feedback between the firms' layoff decision and wages exists. Relaxing this assumption leads to the results presented in section 3.4. Further, GaldónSánches and Güell (2003) assume that $m=z$ and show that it does not make any difference in their analysis if $m \neq z$. In the above model, it makes a difference. Following Galdón-Sánches and Güell (2003), and assuming that $m=z$, we can see that market tightness unambiguously decreases. This can easily be confirmed by equation (21), where the rhs is smaller than unity and $\frac{m}{z}=1$ for $m=z$. From equation (20), we find for $m=z$ that if the indirect cost decrease of wage and search costs is smaller than unity $\left(1>-\frac{1}{c q^{\prime}(\theta) / q(\theta)^{2}} \frac{d w^{e}}{d \theta}\right)$, reservation productivity increases and the results of Galdón-Sánches and Güell (2003) apply. Otherwise, it decreases, which yields an ambiguous effect on unemployment due to an increase of the level of severance payments. 


\section{Conclusion}

This paper contributes to the discussion about severance payments and firing costs if workers' effort is not perfectly observable and judicial mistakes exist when deciding who is entitled to receive a severance payment and who is not. In contrast to Galdón-Sánches and Güell (2003), we allow for endogenous job destruction and job creation, permitting firms to decide when to dismiss a worker. It is shown that when the effects of pure firing costs on unemployment are ambiguous due to fewer dismissals and less job creation. The existence of type I and type II mistake unambiguously increase unemployment. This is mainly due to the fact that the existence of those mistakes increases the incentive of shirking (because through a type I mistake, a shirker might receive the severance payment when dismissed and through a type II mistake, a non-shirker might not receive the severance payment). This increases wages and, therefore, labour costs yielding more dismissals and less job creation. In contrast to the model by Galdón-Sánches and Güell (2003), an increase of the level of severance payments generates ambiguous effects on job destruction and job creation and, therefore, unemployment. We are able to derive conditions for unemployment to increase or decrease, depending on the magnitude of type I and type II mistake. For relatively small (or no) judicial mistakes, an increase of the level of severance payments decreases dismissals and increases job creation. Hence, an increase of the level of severance payments can increase employment.

This paper points out that is is essential to learn more about judicial mistakes when dealing with employment protection in form of severance payments. It gives clear assignments for further research. As the existence of judicial mistakes clearly has negative effects on employment (with and without a change of the level of severance payments), further theoretical research should detect the origin of judicial mistakes as they are taken as exogenously given in the present paper. Additionally, one should find incentives to decrease judicial mistakes. Empirical research should try to clarify the magnitude of judicial mistakes to examine the relevance of dealing with them. As already mentioned, this has not really been tackled. There are hints that such mistakes exist though. If one finds out that they are large and, therefore, of importance, political advice concerning severance payments might have to be changed.

\section{Mathematical Appendix}

\section{A Job Destruction and Job Creation with a Non-Shirking Wage}

To calculate reservation productivity and market tightness, the values of continuing and newly created jobs have to be calculated. Substituting the non-shirking wage, equation(4), 
into equation (5) yields

$$
\begin{aligned}
(r+\lambda) J(\epsilon)= & \bar{e} \epsilon-\left[\left(r+\lambda G\left(\epsilon_{d}\right)+\theta q(\theta)\right]\left[\frac{\bar{e}}{q}+m S\right]-\bar{e}\right. \\
& -\lambda G\left(\epsilon_{d}\right) T+\lambda\left[\int_{\epsilon_{d}}^{\epsilon_{u}} J(x) d G(x)\right] .
\end{aligned}
$$

Therefore, the firm value can be calculated from

$$
(r+\lambda)\left[J(\epsilon)-J\left(\epsilon_{d}\right)\right]=\left(\epsilon-\epsilon_{d}\right) \bar{e}
$$

as

$$
J(\epsilon)=\frac{\left(\epsilon-\epsilon_{d}\right) \bar{e}}{(r+\lambda)}-(T+z S) .
$$

Using equation (23) and using $J\left(\epsilon_{d}\right)=-(T+z S)$ to evaluate equation (22) for the reservation productivity yields

$$
\begin{aligned}
(r+\lambda) J\left(\epsilon_{d}\right)= & -(r+\lambda)(T+z S)=\bar{e} \epsilon_{d}-\left[\left(r+\lambda G\left(\epsilon_{d}\right)+\theta q(\theta)\right]\left[\frac{\bar{e}}{q}+m S\right]\right. \\
& -\bar{e}-\lambda G\left(\epsilon_{d}\right) T-\lambda\left(1-G\left(\epsilon_{d}\right)\right)(T+z S)+\lambda \frac{\bar{e}}{(r+\lambda)} \int_{\epsilon_{d}}^{\epsilon_{u}}\left(x-\epsilon_{d}\right) d G(x)
\end{aligned}
$$

which can be transformed into equation (8).

To calculate the present discounted value of a newly created job, we substitute $\epsilon$ by $\epsilon_{u}$ in equation (23) and use equation (7) which yields equation (9).

\section{B Effects on Reservation Productivity and Market Tight- ness}

We totally differentiate equations (8) and (9) with respect to $\theta, \epsilon_{d}, m, z, S$ and $T$. Then we put the endogenous variables $d \epsilon_{d}$ and $d \theta$ on the lhs, while putting the exogenous ones, $d m$, $d z, d S$ and $d T$ on the rhs. Writing the system of equations as a matrix yields

$$
\begin{aligned}
& \underbrace{\left(\begin{array}{c}
\frac{\bar{e}}{r+\lambda}\left(r+\lambda G\left(\epsilon_{d}\right)\right)-\lambda g\left(\epsilon_{d}\right)\left[\frac{\bar{e}}{q}+(m-z) S\right] \\
-\frac{\bar{e}}{(r+\lambda)}
\end{array}-\left[\begin{array}{c}
\left.\frac{\bar{e}}{q}+m S\right] \\
\frac{c q^{\prime}(\theta)}{q(\theta)^{2}}
\end{array}\right]\right.}_{=B} \begin{array}{c}
{[\theta q(\theta)]^{\prime}} \\
d \theta
\end{array}) \\
= & \left(\begin{array}{c}
\left(r+\lambda G\left(\epsilon_{d}\right)+\theta q(\theta)\right) S \\
0
\end{array}-\left(\begin{array}{c}
d \epsilon_{d} \\
d \theta
\end{array}\right)\right. \\
& \times\left(\begin{array}{c}
d m \\
d z \\
d S \\
d T
\end{array}\right) .
\end{aligned}
$$


With $D=\operatorname{det}(B)$, rearranging equation (24) yields

$$
\begin{aligned}
& \left(\begin{array}{c}
d \epsilon_{d} \\
d \theta
\end{array}\right)=\frac{1}{D}\left(\begin{array}{cc}
\frac{c q^{\prime}(\theta)}{q(\theta)^{2}} & {\left[\frac{\bar{e}}{q}+m S\right][\theta q(\theta)]^{\prime}} \\
\frac{\bar{e}}{(r+\lambda)} & \frac{\bar{e}}{r+\lambda}\left(r+\lambda G\left(\epsilon_{d}\right)\right)-\lambda g\left(\epsilon_{d}\right)\left[\frac{\bar{e}}{q}+(m-z) S\right]
\end{array}\right) \times
\end{aligned}
$$

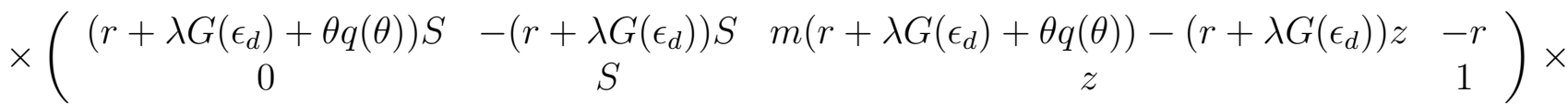

$$
\begin{aligned}
& \times\left(\begin{array}{c}
d m \\
d z \\
d S \\
d T
\end{array}\right)
\end{aligned}
$$

which finally yields equations (14) to (19).

\section{References}

Addison, J. T. and P. Teixeira (2003). "The Economics of Employment Protection", Journal of Labor Research 24 (1), 85-129.

Baker, D., A. Glyn, D. Howell and J. Schmitt (2005). "Labour Market Institutions and Unemployment: A Critical Assessment of Cross-Country Evidence", in: Fighting Unemployment. The Limits of Free Market Orthodoxy, D. R. Howell (edt.), Oxford University Press, New York, pp. 72-118.

Berger, H. (1998). "Regulation in Germany: Some Stylized Facts About Its Time Path, Causes and Consequences", Zeitschrift für Wirtschafts- und Sozialwissenschaften 118(2), 185-220.

Bertola (1990). "Job Security, Employment and Wages", European Economic Review 34, 851-886.

Bertola, G. (1999). "Microeconomic Perspectives on Aggregate Labor Markets", in O.Ashenfelter and D.Card (edt.), Handbook of Labor Economics, Volume 3C, Elsevier, Amsterdam, 29853028.

Bertola, G., T. Boeri, and S. Cazes (1999). "Employment protection and labour market adjustment in OECD countries: Evolving institutions and variable enforcement", ILO Employment and Training Papers 48, Geneva.

Blanchard, O. and P. Portugal (2001). "What Hides Behind an Unemployment Rate: Comparing Portuguese and U.S. Labor Markets", American Economic Review 91, 187-207. 
Broersma, L. and J. C. van Ours (1999). "Job Searchers, Job Matches and the Elasticity of Matching", Labour Economics, Vol. 6(1), pp. 77-93.

Fella, G. (2000). "Efficiency Wage and Efficient Redundancy Pay", European Economic Review 44(8), 1473-1490.

Galdón-Sánches, J. E. and M. Güell (2000). "Let's got to Court! Firing Costs and Dismissal Conflicts", Princeton University, Industrial Relations Section, Working Paper 444.

Galdón-Sánches, J. E. and M. Güell (2003). "Dismissal conflicts and unemployment", European Economic Review 47, 323 - 335.

Garibaldi, P. (1998). "Job Flow Dynamics and Firing Restrictions", European Economic Review 42, 245-275.

Garibaldi, P. and G. L. Violante (2005). "The Employment Effects of Severance Payments with Wage Rigidities", The Economic Journal 113, 799-832.

German Council of Economic Experts (2005). "Die Chance nutzen - Reformen mutig voranbringen", Elsevier Group, Reutlingen.

Goerke, L. (2002). "On Dismissal Pay", Labour Economics 9(4), 497-512.

Goerke, L. and M. Pannenberg (2004). "Berufliche Weiterbildung "on-the-job" und Auflösung von Beschäftigungsverhältnissen", Diskussionspapier der Forschergruppe 'Heterogene Arbeit' $04 / 22$.

Güell, M. (1999). "Employment Protection and Unemployment in an Efficiency Wage Model", Princeton University, Industrial Relations Section, Working Paper 432.

Ichino, A., M. Polo, and E. Rettore (2003). "Are judges biased by labor market conditions?", European Economic Review 47, 913-944.

Kittner, M. (2000). "Kündigungsschutz in Deutschland und den USA", Betriebs-Berater 55, Beilage 4.

Mortensen, D. T. and C. Pissarides (1999). "New Developments in Models of Search in the Labor Market", in O.Ashenfelter and D.Card (edt.), Handbook of Labor Economics, Volume 3B, Elsevier, Amsterdam, 2567-2627. 
OECD (2004). "Employment Outlook", Paris.

Pissarides, C. (2000). "Equilibrium Unemployment Theory", Cambridge USA: MIT Press.

Pissarides, C. (2001). "Employment Protection", Labour Economics 8, 131-159.

Riphahn, R. T. (2004). "Employment Protection and Effort among German Employees", Economic Letters 85 (3), 353-357.

Scarpetta, S. (1996). "Assessing the Role of Labour Market Policies and Institutional Setting on Unemployment: A Cross-country Study", in OECD: Economic Studies 26, 43-98.

Shapiro, C. and J. M. Stiglitz (1984). "Equilibrium Unemployment as a Worker Discipline Device", American Economic Review 74, 433-444.

Staffolani, S. (2002). "Firing Costs, Efficiency Wages and Unemployment", Labour 16 (4), 803-830. 